\begin{tabular}{|l|l|l|}
\hline \multicolumn{2}{|c|}{ PublisherInfo } \\
\hline \hline PublisherName & $:$ & BioMed Central \\
\hline \hline PublisherLocation & $:$ & London \\
\hline \hline PublisherImprintName & $:$ & BioMed Central \\
\hline \hline
\end{tabular}

\title{
Pokemon's cancer role revealed
}

\begin{tabular}{|l|c|l||}
\hline \multicolumn{2}{|c|}{ ArticleInfo } \\
\hline \hline ArticleID & $:$ & 5053 \\
\hline \hline ArticleDOI & $:$ & $10.1186 /$ gb-spotlight-20050120-01 \\
\hline \hline ArticleCitationID & $:$ & spotlight-20050120-01 \\
\hline \hline ArticleSequenceNumber & $:$ & 29 \\
\hline \hline ArticleCategory & $:$ & Research news \\
\hline ArticleFirstPage & $:$ & 1 \\
\hline \hline ArticleLastPage & $:$ & 3 \\
\hline \hline & & RegistrationDate : 2005-1-20 \\
\hline ArticleHistory & $:$ & OnlineDate \\
\hline \hline ArticleCopyright & $:$ & BioMed Central Ltd2005-1-20 \\
\hline \hline ArticleGrants & $:$ & \\
\hline \hline ArticleContext & $:$ & 130596611 \\
\hline \hline
\end{tabular}


Email: paterlm@mail.rockefeller.edu

Scientists at Memorial Sloan-Kettering Cancer Center (MSKCC) report in Nature this week that they have identified a new cellular oncogene (Nature 2005, 433:278-2850.

The team led, by cancer geneticist Pier Paolo Pandolfi, showed for the first time that the so-called Pokemon gene - which shares a name with a Japanese cartoon popular with children - functions as a proto-oncogene repressing the tumor suppressor ARF.

"This is a very elegant paper," said Gary Gilliland, a Howard Hughes scholar at Harvard Medical School, who did not participate in the study. "The observations of Dr. Pandolfi and his colleagues provide new insights into mechanisms of tumorigenesis."

Gilliland noted that loss of function of critical tumor suppressors may occur through mutation or deletion and that decreased expression due to epigenetic modifications may also explain loss of function of tumor suppressors.

"Several lines of evidence in this report indicate that a novel mechanism of inhibition of expression of tumor suppressors, such as ARF, by transcriptional repression mediated by Pokemon, may also contribute to development of cancers," Gilliland told us.

Pokemon, which stands for POK erythroid myeloid ontogenic factor, belongs to the POK family (POZ domain and Kruppel zinc fingers) of transcriptional factors. If mutated, they become transcriptional repressors through the engagement of histone deacetylases, causing chromatin remodeling and in turn tumorigenesis.

Pokemon was already known to be crucial in cellular differentiation and to physically interact with other members of the POK family. These facts made Pokemon an appealing molecule to investigate further.

To nail down the role of Pokemon in oncogenesis, Pandolif's team used in vitro and in vivo approaches. They established that Pokemon is an oncogene by coexpressing it in mouse embryonic fibroblasts (MEFs) with other well established oncogenes, such as Myc, H-ras, and $T$-Ag.

"Oncogenes always work in tandem and never alone, and Pokemon coexpression blocks oncogeneinduced apoptosis and senescence," Pandolfi told us. "And even more interesting, by switching off Pokemon, other oncogenes were blocked too."

The same effect was described in vivo. Mouse embryonic fibroblasts lacking the gene coding for Pokemon proliferate but do not replicate, the MSKCC team found. In light of this scenario, a drug acting in the same way could represent a promising attack against this oncogenic network.

Conversely, in transgenic mice in which Pokemon is specifically overexpressed, aggressive tumors develop. "Pokemon might play the role of 'master' in the regulation of the transformation activity, controlling the pathways that are required to transform normal cells into cancerous ones," Pandolfi suggested. 
In a second set of experiments including a serial of transcriptional assays, such as cyclic amplification and selection targets, electrophoresis mobility shift assay, and chromatin immuno-precipitation, the team traced the molecule regulated by Pokemon. Researchers identified Pokemon binding sites in the ARF promoter. After mutating these sites, they could rescue ARF activity.

ARF, which induces cellular senescence in response to oncogenic inputs, is therefore directly downregulated by Pokemon.

Scott Lowe of Cold Spring Harbor Laboratory in New York, who wasn't involved in the research, told us the results were very interesting. "The connection between a new transcriptional regulator and an established tumor suppressor pathway with important implications for tumorigenesis is very exciting," he said.

"Not only did we accumulate genetics proofs," said co-author Carlos Cordon-Cardo, director of the Division of Molecular Pathology at MSKCC, "but we also collected clinical and pathological proofs. Indeed, performing tissue microarray analysis, we noticed an abnormal expression of Pokemon in human cancer, in particular in two subsets of lymphoma. What we are eager to do now is to define a more accurate clinical and pathological profile of Pokemon."

\section{References}

1. Nature, [http://www.nature.com]

2. Pier Paolo Pandolfi, [http://www.mskcc.org/mskcc/html/10345.cfm]

3. INK4a/ARF mutations accelerate lymphomagenesis and promote chemoresistance by disabling p53

4. D. Gary Gilliland, [http://www.hhmi.org/research/investigators/gilliland_bio.html]

5. Scott Lowe, [http://www.cshl.org/public/SCIENCE/lowe.html]

6. Carlos Cordon-Cardo, [http://www.mskcc.org/prg/mrg/bios/272.cfm] 